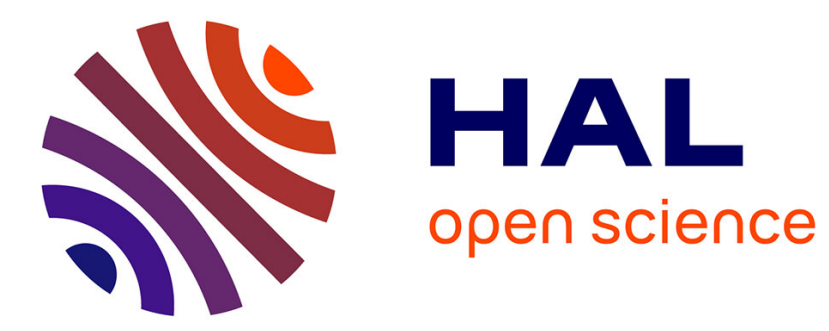

\title{
Modelling crack propagation due to growth stress release in round wood \\ Delphine Jullien, Joseph Gril
}

\section{To cite this version:}

Delphine Jullien, Joseph Gril. Modelling crack propagation due to growth stress release in round wood. Journal de Physique IV Proceedings, 2003, 105, pp.265-272. 10.1051/jp4:20030196 . hal-02001175

\section{HAL Id: hal-02001175 \\ https://hal.science/hal-02001175}

Submitted on 31 Jan 2019

HAL is a multi-disciplinary open access archive for the deposit and dissemination of scientific research documents, whether they are published or not. The documents may come from teaching and research institutions in France or abroad, or from public or private research centers.
L'archive ouverte pluridisciplinaire HAL, est destinée au dépôt et à la diffusion de documents scientifiques de niveau recherche, publiés ou non, émanant des établissements d'enseignement et de recherche français ou étrangers, des laboratoires publics ou privés. 


\title{
Modelling crack propagation due to growth stress release in round wood
}

\author{
D. Jullien and J. Gril
}

\author{
Laboratoire de Mécanique et Génie Civil, Université Montpellier 2, UM2-LMGC-Bois, CC. 81, \\ place E. Bataillon, 34095 Montpellier cedex 5, France
}

\begin{abstract}
The propagation of heart cracks at $\log$-ends due to growth stress release was simulated numerically based on the application of Griffith theory. The elastic properties of the green wood were described through empirical correlations with density distinguishing hardwoods and softwoods. Fixed levels of surface residual strains and a given type of initial growth stress distribution were assumed. The propagation criteria was based on the maximisation of elastic release energy rate (G). Perfect axisymmetry was compared to the case of a marked reaction wood sector: the simulation confirmed the observed fact that in hardwoods, the presence of tension wood increases considerably the cracking risk, while it is reduced with the compression wood of softwoods. By comparison of the calculated $G$ to experimental data of toughness $\left(\mathrm{G}_{\mathrm{c}}\right)$, our calculations suggest that not only higher log diameter but also higher wood density should result in more severe log-end cracks.
\end{abstract}

\section{INTRODUCTION}

Log-end cracks consecutive to tree felling and crosscutting are a clear demonstration of the existence of residual stresses in living stems [1]. These so called growth stresses result from the cell-wall maturation process, where newly formed wood swells transversally and, in normal wood, shrinks axially. In the case of "reaction wood" production on one side of the stem, this axial strain differs: in the tension wood of hardwoods, a much higher shrinkage is produced, whereas in the compression wood of conifers, it is a swelling; in all cases the dissymmetric growth stress allows the control of stem orientation. Crosscutting can be analysed as the creation of a free surface in a prestressed volume; the consecutive stress redistribution is equivalent to the axial pulling of the heart and pressure of the periphery, which favours the central splitting of the log ends. Subsequent sawing induces further transformation defects like board deformation or further splitting along the pith. These phenomena, more considerable in the case of hardwoods and tension wood occurrence, have been extensively reviewed [2], along with useful considerations about their viscoelastic nature and hygrothermal activation. From the viewpoint of solid mechanics, crack propagation under the action of a mechanical stress can be analysed using energetic concepts derived from Griffith theory [3]. Our work aims at checking how well such mechanical analysis can explain the observed patterns of log-end cracks. In a previous work, a method of numerical analysis has been proposed and validated: the rate of release energy was computed based on a set of experimental data obtained on Eucalyptus and compared to actual values of toughness measured on the same or similar material [4-5]. In the present paper we will apply this method to a larger number of theoretical situations covering the range of what can be expected from the various wood species, essentially differing by the level of their anisotropy.

\section{THEORY AND NUMERICAL METHOD}

\subsection{Formulation of the mechanical problem}

The analysis of crack propagation used here is based on the 2 nd principle of thermodynamics, leading to the incremental expression:

$$
\mathrm{G}_{\mathrm{c}} \mathrm{dA}+\mathrm{dW}<0 \text { or }-\mathrm{dW} / \mathrm{dA}>\mathrm{G}_{\mathrm{c}}
$$

where $\mathrm{dW}$ is the variation of elastic energy stored in the body, when the crack area extends by $\mathrm{dA}$, and $\mathrm{G}_{\mathrm{c}}$ is 
the energy consumed per creation of a unit area of crack. The contribution of dynamic terms has been neglected, and no external load is acting on the volume. According to Griffith theory, the toughness $\mathrm{G}_{\mathrm{c}}$ is an intrinsic property of the material, and can be determined experimentally for any orientation of crack surface (and fracture mode). The quasi-fragile behaviour of wood loaded transversally to the fibres justify the application of this theory originally designed for crack propagation in glass, and the observed dominance of an opening mode (mode I) will allow to neglect the contribution from other fracture modes. Equation (1) can be also written $G>G_{c}$, where $G=-\delta \mathrm{W} / \delta \mathrm{A}$ is the "elastic energy release rate". $\mathrm{G}$, in contrast to $G_{c}$, depends on the geometry and behaviour of the whole structure, as well as on its formation and loading history because the initial stress distribution in the log depends strongly on the way the successive wood rings were deposited. The evaluation of $\mathrm{G}$, therefore, requires a calculation based on a mechanical model.

To compute the energy release, additional assumption on the material behaviour is required. A linear relationship is assumed between the stress $\sigma$ and the small strain $\varepsilon: \varepsilon=S \sigma$, where $S$ is the compliance tensor. The linearity of this expression allows to use as reference the initial state of the log just before felling $\left(\sigma^{\mathrm{i}}\right)$ :

$$
\Delta \varepsilon=\mathrm{S} \Delta \sigma
$$

where $\Delta \varepsilon$ is the deformation relative to the state before felling, and $\Delta \sigma$ the corresponding stress increase. After propagation of a crack up to a given level of free surface (A), a condition of zero force has to be written for all points of (A):

$$
0=\sigma \cdot n=\left(\sigma^{\mathrm{i}}+\Delta \sigma\right) \cdot \mathrm{n} \quad \text { or } \quad \Delta \sigma \cdot n=-\sigma^{\mathrm{i}} \cdot \mathrm{n}
$$

where $n$ is a unit vector perpendicular to the surface (A), which includes the free surface created by crosscutting the log. Thus, the existence of the free surface has the same effect as applying a force opposed to that existing in the standing log. Adding to (2) and (3) conditions of static equilibrium and kinematic compatibility, we end up with a well-formulated mechanical problem having a single solution $\Delta \sigma$ and associated strain $\Delta \varepsilon$. The energy required for the calculation of $\mathrm{G}$ can be obtained as the elastic energy by integration over the whole volume:

$$
\mathrm{W}=\frac{1}{2} \int(\sigma+\Delta \sigma) \cdot \mathrm{S} \cdot(\sigma+\Delta \sigma) \mathrm{dv}
$$

Assuming an initial stress field locked in a standing tree, we can calculate the corresponding amount of elastic energy stored in a log crosscut off this tree. Assuming that a given heart crack appears in the pith of this same log, we can calculate the amount of elastic energy released by the existence of this new surface.

\subsection{Geometry and mesh}

Calculations are conducted using the finite element package MODULEF. The $\log$ is assumed cylindrical, with radius $\mathrm{R}=0.1 \mathrm{~m}$ and height $2 \mathrm{~h}=1.4 \mathrm{~m}$, and contains a central pith represented by a hole of radius $R_{0}=0.002 \mathrm{~m}$. In [5] it was verified that for this value of $R_{0}$ this was practically equivalent, in terms of global energy computation, to having a filled pith, while greatly simplifying the constitution of the mesh. The crack shape is shown on Figure 1: it is quasi-triangular with a depth $\mathrm{H}$ at the pith

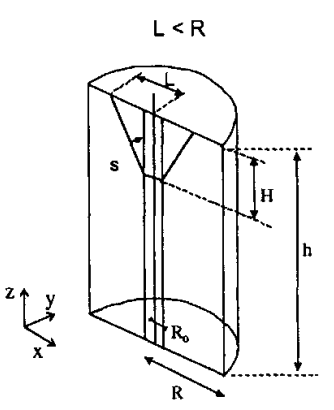

Figure 1. Description of the cracks (upper half of the log) level and a radial length $L$ on the log end. When the periphery has been reached $(L=R)$ a lateral opening $D$ appears. Only the upper half of the $\log (0<\mathrm{z}<\mathrm{h})$ is simulated, assuming a symmetrical behaviour of the log. As suggested by observations [6], the crack propagates through a vertical translation, with a constant shape ratio (s) called "crack slope":

$$
\mathrm{s}=\mathrm{H} /\left(\mathrm{L}-\mathrm{R}_{0}\right) \quad \text { for } \mathrm{L}<\mathrm{R} \quad ; \mathrm{s}=(\mathrm{H}-\mathrm{D}) /\left(\mathrm{R}-\mathrm{R}_{0}\right) \text { for } \mathrm{L}=\mathrm{R}
$$

For convenience, the extent of a crack will be described later by its "equivalent crack length" $L$ ' $=L+D / s$.

The elements constituting the mesh are hexaedral. Based on a previous study [4-5], we chose $N_{R}=10$ elements along the radius and $\mathrm{N}_{\mathrm{T}}=16$ sectors around the periphery. 


\subsection{Constitutive equations}

Wood can be reasonably considered as orthotropic, with the transverse plane RT (neglecting stem conicity) and the radial plane RL constituting two orthogonal planes of material symmetry. A major simplifying assumption made here is neglecting any occurrence of spiral grain or eccentric growth, that would produce a rotation of the axes relative to the $\mathrm{R}$ and $\mathrm{L}$ direction, respectively: the local directions of orthotropy coincide with the cylindrical coordinates (cylindrical orthotropy).

Guitard [7] proposed, based on a compilation of data from the literature, a set of empirical equations giving each component $S_{i j}$ of the compliance tensor as a function of the air-dry specific gravity of the wood $(\rho)$ and the moisture content $(h)$, of the form:

$$
\frac{1}{S_{i j}}(\text { in GPa })=\left[1-e_{i j}(h-0.12)\right] \times \begin{cases}a_{i j}(\rho / 0.65)^{b_{i j}} & \text { for hardwoods } \\ c_{i j}+d_{i j}(\rho-0.45) & \text { for softwoods }\end{cases}
$$

where $\mathrm{a}_{\mathrm{ij}} \ldots \mathrm{e}_{\mathrm{ij}}$ are constants recalled in Table 1 . Table 2 shows the various sets of rigidity values that will be actually used in the following simulations. A fixed value of $h=0.3$ has been used to account for the fact that the wood of recently cut logs is generally saturated in bound water. Instead of the $S_{i j}$, we indicated the "technical constants": Young's moduli, shear moduli, Poisson's ratios, together with three dimensionless factors characterizing the level of anisotropy: $\mathrm{E}_{\mathrm{V}} / \mathrm{E}_{\mathrm{R}}, \mathrm{E}_{\mathrm{R}} / \mathrm{E}_{\mathrm{T}}, \mathrm{E}_{\mathrm{T}} / \mathrm{G}_{\mathrm{RT}}$. It can be noted that for hardwoods, the lower the density, the higher the anisotropy: this is due to the increasing contribution of the highly oriented cellular structure of wood, when the cell wall thickness decreases. For softwoods varying over a small range of density, the effect is small but opposite. Compared with hardwoods of the same density, softwoods have a much lower $\mathrm{G}_{\mathrm{RT}}$ (their are much more anisotropic in the RT plane than hardwoods) as well as a higher $\mathrm{E}_{\mathrm{L}}$.

Table 1. Parameters describing the dependence of compliance coefficients on density and humidity

\begin{tabular}{|c|c|c|c|c|c|c|c|c|c|}
\hline $\mathrm{ij}$ & 11 & 22 & 33 & 23 & 13 & 12 & 44 & 55 & 66 \\
\hline $\mathrm{a}_{\mathrm{ij}}$ & 1.81 & 1.03 & 14.4 & -31.2 & -37.3 & -2.68 & 0.971 & 1.26 & 0.366 \\
\hline $\mathrm{b}_{\mathrm{ij}}$ & 1.3 & 1.74 & 1.03 & 1.09 & 0.913 & 1.41 & 1.26 & 1.14 & 1.74 \\
\hline $\mathrm{c}_{\mathrm{ij}}$ & 1 & 0.636 & 13.1 & -30.8 & -34.2 & -2.05 & 0.745 & 0.861 & 0.0836 \\
\hline $\mathrm{d}_{\mathrm{ij}}$ & 2.37 & 1.91 & 41.7 & 101 & 117 & 5.28 & 0.989 & 2.08 & 0.228 \\
\hline $\mathrm{e}_{\mathrm{ij}}$ & 3 & 3 & 1.5 & 0 & 0 & 0 & 3 & 3 & 3 \\
\hline
\end{tabular}

Table 2. Sets of elastic constants used for the simulation

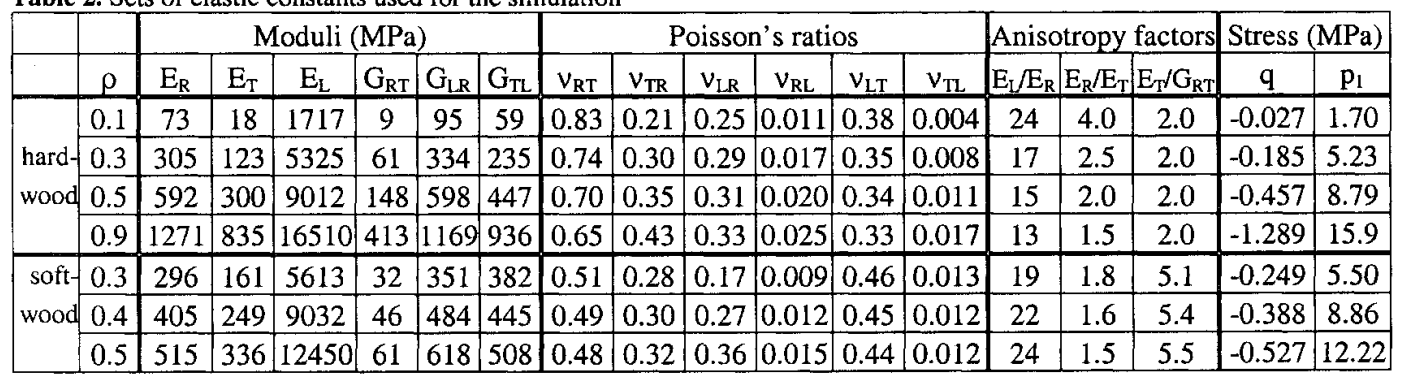

Although these expressions provide with reasonable estimates of the mean values of wood species, within a given species the compliance of wood cannot be considered as only dependent on the density. For instance, the longitudinal Young's modulus would be more adequately described as the product of density and a function of the mean inclination of the crystalline cellulose in the cell wall (microfibrillar angle). However, this complexity was not introduced in the present set of simulation, and density alone was used for the description of wood anisotropy. In particular, the influence of tension wood occurrence on the rigidity is not taken into consideration.

\subsection{Initial growth stress distribution}

At stem periphery a state of plane stress can be assumed, so that the $\mathrm{T}$ and $\mathrm{L}$ components of the growth stress $\sigma^{\mathrm{i}}$ are related to those of the residual strain $\alpha=-S \sigma^{\mathrm{i}}$, by:

$$
\sigma_{\mathrm{L}}^{\mathrm{i}}=-\mathrm{E}_{\mathrm{L}}\left[\alpha_{\mathrm{L}}+v_{\mathrm{TL}} \alpha_{\mathrm{T}}\right] /\left(1-v_{\mathrm{LT}} v_{\mathrm{TL}}\right) ; \sigma_{\mathrm{T}}^{\mathrm{i}}=-\mathrm{E}_{\mathrm{T}}\left[\alpha_{\mathrm{T}}+v_{\mathrm{LT}} \alpha_{\mathrm{T}}\right] /\left(1-v_{\mathrm{LT}} v_{\mathrm{TL}}\right)
$$


Most available data relate to values of $\alpha_{\mathrm{L}}$ and a few to $\alpha_{\mathrm{T}}$; they do not vary much between species, being more dependent on the growth condition of the tree than on wood density, for instance. We will assume fixed reference values $\alpha_{\mathrm{L}}^{\circ}=-0.1 \%$ and $\alpha_{\mathrm{T}}^{\circ}=0.2 \%$, meant to represent normal wood [1]. In a zone containing tension or compression wood, $\sigma_{L}^{\mathrm{i}}$ will become higher or lower, respectively, while $\sigma_{R}^{\mathrm{i}}$ and $\sigma_{\mathrm{T}}^{\mathrm{i}}$ will be unchanged.

To describe fully the initial stress distribution, a number of further assumptions will have to be made. The initial growth stress, in the standing tree, is supposed independent of the axial coordinate $\mathrm{z}$. The transverse components are axisymmetric, obtained by generalization of Kübler's model $[1,2]$ which is obtained when $k$ tends towards 0 , and given as a function of the relative distance to pith $r / R$, by:

$$
\sigma_{\mathrm{R}}^{\mathrm{i}}(\mathrm{r})=\mathrm{q}\left[(\mathrm{r} / \mathrm{R})^{\mathrm{k}}-1\right] / \mathrm{k} \quad ; \quad \sigma_{\mathrm{T}}^{\mathrm{i}}(\mathrm{r})=\mathrm{q}\left[(1+\mathrm{k})(\mathrm{r} / \mathrm{R})^{\mathrm{k}}-1\right] / \mathrm{k}
$$

where $\mathrm{q}$ is the surface stress in $\mathrm{T}$ direction, and $\mathrm{k}$ a constant. In $\mathrm{L}$ direction, we have to take into account the presence of reaction wood. An asymmetric term is added so as to fit with peripheral values of residual stresses usually measured on standing trees [1]:

with:

$$
\begin{aligned}
& \sigma_{\mathrm{L}}^{\mathrm{i}}(\mathrm{r})=\mathrm{p}_{1} \mathrm{f}\left(\mathrm{r} / \mathrm{R} ; \mathrm{k}_{1}\right)+\mathrm{p}_{2} \mathrm{f}\left(\mathrm{r} / \mathrm{R} ; \mathrm{k}_{2} \mathrm{~g}[\theta ; \mathrm{m}]\right) \mathrm{g}[\theta ; \mathrm{m}] \\
& \mathrm{f}(\mathrm{x} ; \mathrm{k})=(2+\mathrm{k}) \mathrm{x}^{\mathrm{k}} / \mathrm{k}-2 / \mathrm{k} \quad ; \mathrm{g}(\theta ; \mathrm{m})=2^{-\left.\frac{\theta-\theta_{0}}{\Delta \theta}\right|^{\mathrm{m}}}
\end{aligned}
$$

where $\theta$ is the angular position in the cylindrical system, $\theta_{0}$ the peak direction, $2 \Delta \theta$ the peak width, $\mathrm{m}$ a shape factor of the peak, $\mathrm{p}_{1}$ the level of the axisymmetric part, $\mathrm{p}_{2}$ that of the additional asymmetric part, $\mathrm{k}_{1}$, $\mathrm{k}_{2}$ and $\mathrm{m}$ factors characterizing the shape of the radial profiles and circumferential distributions. For the simulations, we will choose $\mathrm{m}=2$ and $\mathrm{k}=\mathrm{k}_{1}=\mathrm{k}_{2}=1 . \mathrm{q}$ and $\mathrm{p}_{1}$ are calculated in each case from equation (8) for $\alpha=\alpha^{\circ}$, while $\mathrm{p}_{2}$ will be taken as 0 to simulate the "axisymmetric" case of no reaction wood at all, and as $2 \mathrm{p}_{1}$ or $-2 p_{1}$ to represent the occurrence of tension wood in hardwoods or compression wood in softwoods, respectively. Values of $q$ and $p_{1}$ for each wood type have been added to Table 2 .

\subsection{Crack propagation}

Only radial cracks are allowed, always starting from the pith: we know from experience that this is the most common fracture mode in freshly cut stems (possible occurrence of ring shakes is not accounted for). We further simplified the problem by allowing only 8 directions of crack propagation, every $45^{\circ}$. Initially, the ends of the log are crack free: the effect of crosscutting only is computed. Then an initial crack of length $\left(\mathrm{R}-\mathrm{R}_{0}\right) / \mathrm{N}_{\mathrm{R}}$ in each of the 8 possible directions is attempted; the direction producing the maximum $\mathrm{G}$ is selected. This process is repeated, producing either the prolongation of an existing crack or the apparition of a new one until at least one crack has reached the periphery and run along the stem surface by a length $\mathrm{kR} / 2$. Although the mesh is rather coarse, it is maintained fixed for all simulation, allowing to study the sole effect of material properties. In a separate work [4], we verified that the use of a finer mesh would not influence much the calculated values of energy release.

\section{RESULTS AND DISCUSSION}

Figure 2a shows, as an illustration, the result obtained in the case of a hardwood of density 0.5 , in the case of a log containing a sector of tension wood and a crack progressing with a fixed slope of 1 . The scatter observed in the progression of $G$ values is easily explained by the roughness of the mesh. While several crack branches progress simultaneously in different directions, the calculation is only made for each branch in turn. This is made clear by plotting in parallel the maximum equivalent crack length $L_{\max }$. In Figure $2 b, G$ is plotted against $L_{\max }$ : the dots are the various values calculated, while the line is obtained by joining the mean values of $G$ for each $L_{\max }$. This parameter, however, does not contain all the important information. It has to be completed by a detailed description of the cracking pattern.

This has been done in Table 3 showing, for each of the computed cases, the crack pattern at three stages characterized by $L_{\max } / R=1 / 2,1$ and $3 / 2$, while Figures 3 and 4 show curves of elastic energy release rate constructed as explained in Figure $2 b$, for the 16 computed cases grouped in various ways to allow comparisons. Figure 3 illustrates the effect of density and reaction wood, in the case of a crack slope $s=1$, and Figure 4 compares a slope of 1 and 2 for a given density of 0.5 . In all cases the effect of having a sector 
of reaction wood, marked by filled symbols, is drastic but opposite for hardwoods and softwoods. In hardwoods, tension wood generally increases the level of initial growth stress, whereas in the compression wood of softwoods the absolute value of the initial stress was made lower in the simulation. For a given biomechanical efficiency, characterized here by the stress difference between the two sides of the stem $\left(2 p_{1}\right.$ at periphery), the amount of locked-in elastic energy should be much higher in hardwoods than in softwoods. This difference would have been further amplified by taking into account the lower $E_{L}$ of softwoods and higher $E_{L}$ of hardwoods. It is consistent with the observed fact that log-end cracks are not a problem in softwood species, but cause severe damage in hardwoods especially in the case of tension wood occurrence.

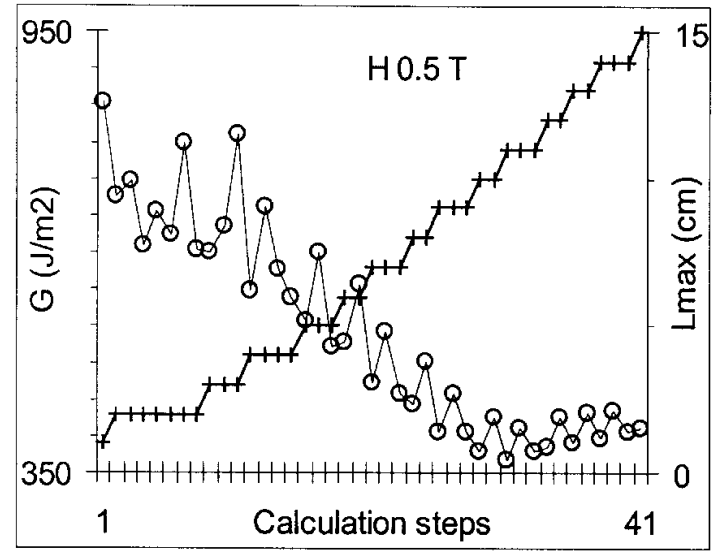

a)

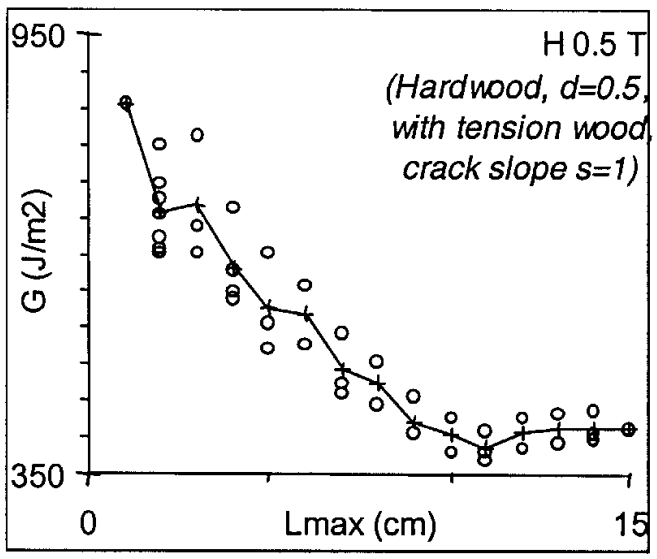

b)

Figure 2. Example of result analysis. (a) step-by-step evolution of elastic energy release rate (G) and maximum equivalent crack length $\left(\mathrm{L}_{\max }\right)$; (b) Construction of a $\mathrm{G}$ vs $\mathrm{L}_{\max }$ curve.

The effect of density can be seen very clearly on Figure 3: denser woods are more rigid, so that they release more energy. It is also interesting to observe the progressive change of cracking pattern with density: in the axisymmetric case, the very low-density hardwood $(\rho=0.1)$ produced 4 cracks, then for $\rho=0.3$ we obtained 3 cracks and from 0.5 upward only 2 opposite cracks; for softwood the 4 cracks were obtained for $\rho=0.3$ but it falled to 2 cracks for 0.4 and 0.5 . In the case of a reaction wood sector, not only the number of cracks is of interest, but also their orientation relative to this sector. In hardwoods, the 4-cracks pattern prevailed up to $\rho=0.5$, with 2 opposite major crack branches running perpendicular to the tension wood zone; in softwoods also the cracks tend to avoid the compression wood sector. But for the hardwood with $\rho=0.9$, on the contrary, one of the two branches cuts the tension wood sector in two halves. The higher crack slope produces markedly different cracking patterns compared to their equivalent for the same density, for instance we obtained 3 branches for the axisymmetric hardwood or the softwood with a compression wood sector.

The effect of density can be seen very clearly on Figure 3: denser woods are more rigid, so that they release more energy. It is also interesting to observe the progressive change of cracking pattern with density: in the axisymmetric case, the very low-density hardwood $(\rho=0.1)$ produced 4 cracks, then for $\rho=0.3$ we obtained 3 cracks and from 0.5 upward only 2 opposite cracks; for softwood the 4 cracks were obtained for $\rho=0.3$ but it falled to 2 cracks for 0.4 and 0.5 . In the case of a reaction wood sector, not only the number of cracks is of interest, but also their orientation relative to this sector. In hardwoods, the 4-cracks pattern prevailed up to $\rho=0.5$, with 2 opposite major crack branches running perpendicular to the tension wood zone; in softwoods also the cracks tend to avoid the compression wood sector. But for the hardwood with $\rho=0.9$, on the contrary, one of the two branches cuts the tension wood sector in two halves. The higher crack slope produces markedly different cracking patterns compared to their equivalent for the same density, for instance we obtained 3 branches for the axisymmetric hardwood or the softwood with a compression wood sector. 
Table 3. Patterns of log end cracks for each simulation, at three steps of the crack propagation (italic numbers refer to the corresponding $\mathrm{G}$ value; segments exceeding the circle represent cracks running along the lateral surface)

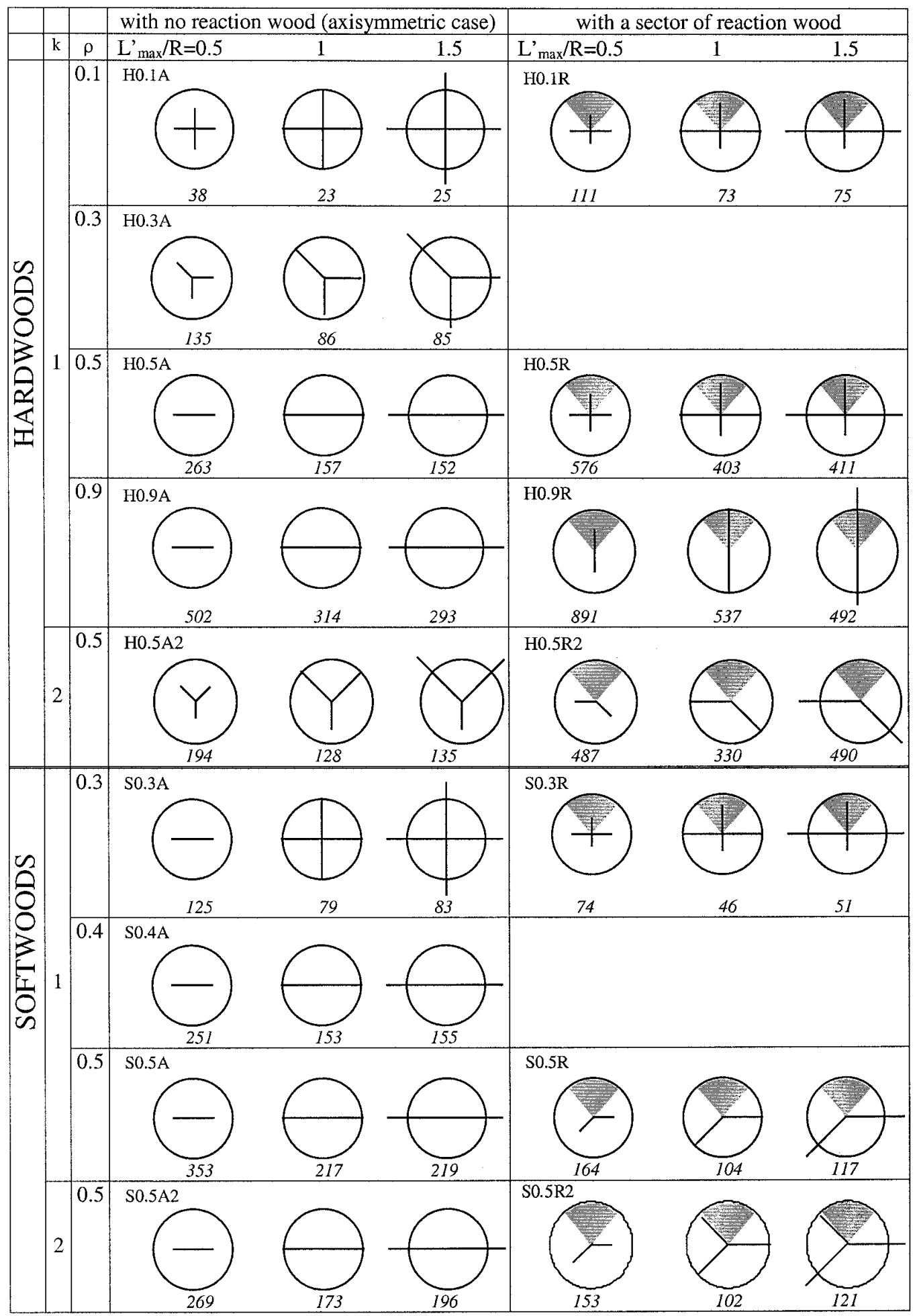




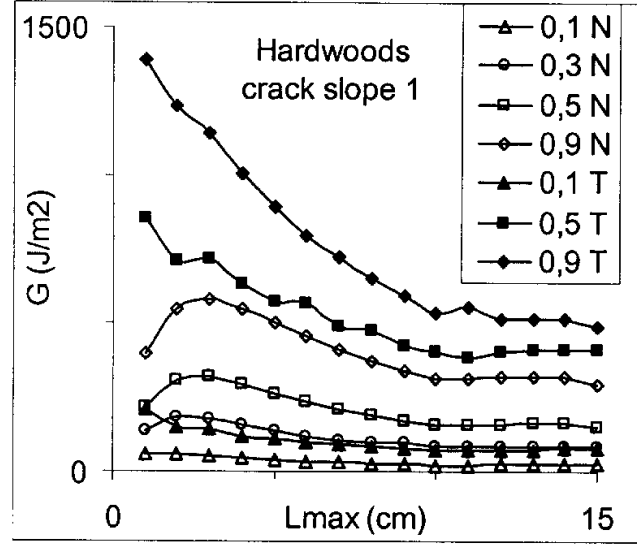

a)

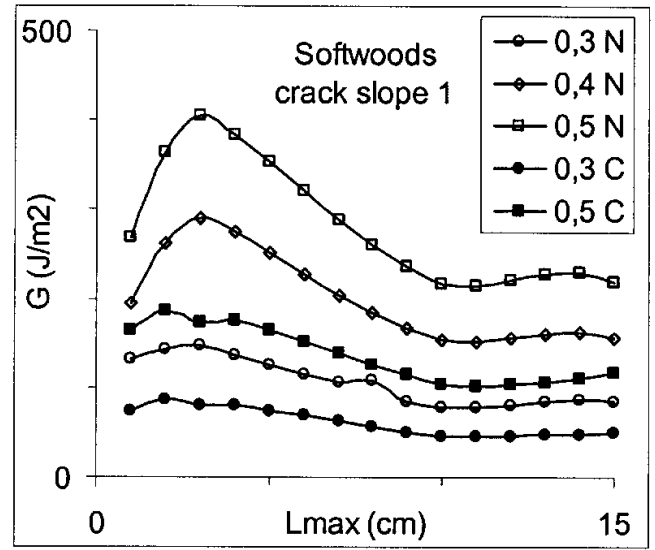

b)

Figure 3. Effect of density and reaction wood occurrence on the evolution of elastic energy release rate versus maximum equivalent crack length. (a) Hardwoods of density 0.1 to 0.9 , (b) Softwoods of density 0.3 to 0.5 . Empty symbols: no reaction wood; Filled symbols: sector of reaction wood.

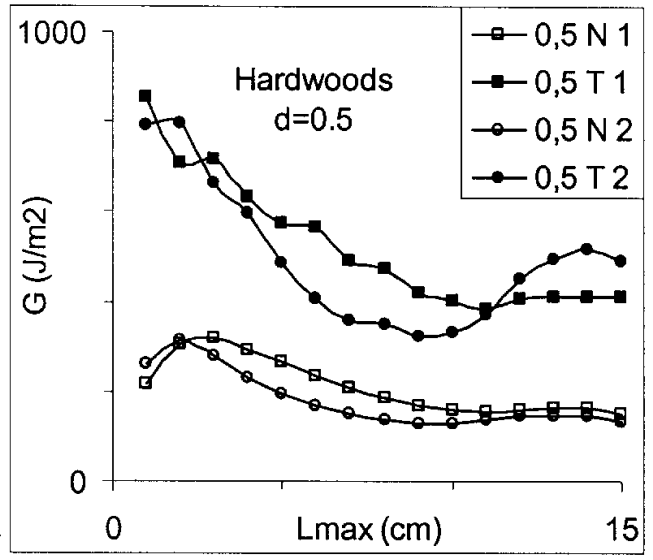

a)

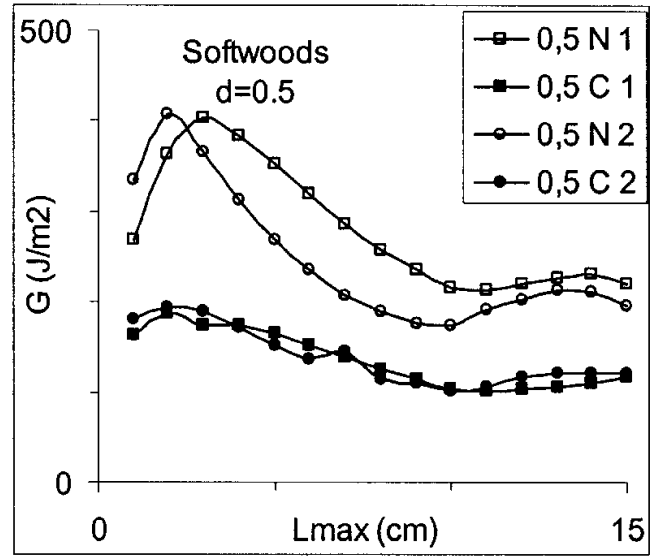

b)

Figure 4. Effect of crack slope on the evolution of elastic energy release rate versus maximum equivalent crack length. (a) Hardwoods (b) Softwoods. Density is 0.5 in all cases. Empty symbols: no reaction wood; Filled symbols: sector of reaction wood.

The curves of Figure 3 and 4 usually present a maximum $G_{\max }$ at an early stage, which in some cases seems to have been hidden by the roughness of the mesh, then fall to a minimum $G_{\min }$ when the crack is more or less reaching the periphery ( $\mathrm{Lmax}=10 \mathrm{~cm}$ in the present case). When the material toughness $\mathrm{G}_{\mathrm{c}}$ lies between these two values, it can be predicted that a crack will occur at log end with an extension so that $\mathrm{G}=\mathrm{G}_{\mathrm{c}}$, assuming that defects around the pith to have allowed enough crack initiation. For $\mathrm{G}_{\max }<\mathrm{G}_{\mathrm{c}}$ no crack should propagate and for $\mathrm{G}_{c}<\mathrm{G}_{\min }$, considerable cracking is expected. In Figure 5a, we have compared our $G_{\max }$ and $G_{\min }$ values for hardwoods to $G_{c}$ values proposed by Beauchêne [8], based on an experimental study on 10 tropical species of increasing density. According to this figure, low density hardwoods should hardly crack unless they contain a lot of tension woods, while high density hardwoods should crack considerably unless they contain very few tension wood.

However, this conclusion is only valid for the given case of log geometry that has been simulated. For a higher $\log$ radius $R_{1}>R$, the elastic release energy would be multiplied by $\left(R_{1} / R\right)^{3}$ and the cracked surface by $\left(R_{1} / R\right)^{2}$, so that the $G$ should increase like $\left(R_{1} / R\right)$ : In Figure $5 b$ we have translated the $G$ values to account for a radius of $20 \mathrm{~cm}$ instead of $10 \mathrm{~cm}$ : we predict then a considerable cracking except in very low density wood with no tension wood. This theoretical effect of the log radius is consistent with observed facts: bigger logs crack relatively more than smaller ones. The effect of density, however, is not so well-known and should be studied systematically by simultaneously measuring log end cracks and wood toughness. 


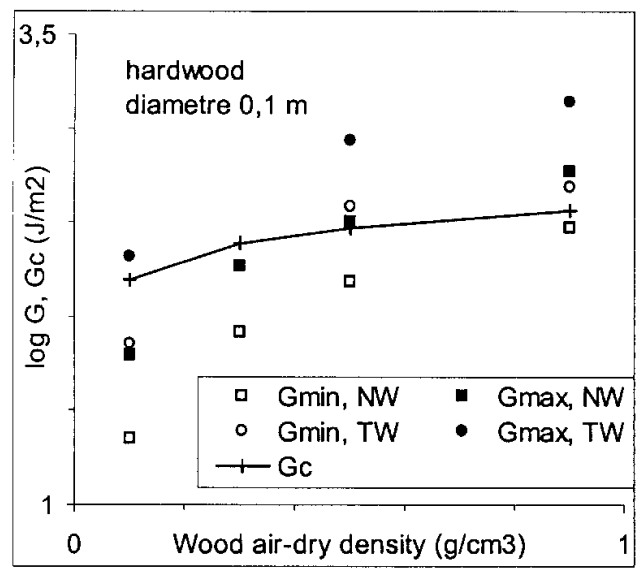

a)

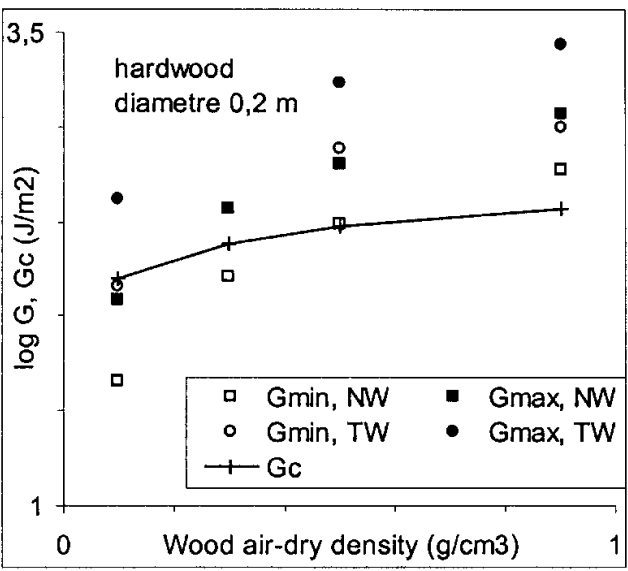

b)

Figure 5. Influence of density on the crack propagation risk, evaluated by comparing the range of calculated values between minima (empty plots) and maxima (filled plots) of $G$ to typical values of the toughness $G_{c}$. (a) Present simulations for $R=10 \mathrm{~cm}$; (b) extrapolation for $\mathrm{R}=20 \mathrm{~cm}$ by a vertical translation in a logarithmic scale.

\section{CONCLUSION}

The propagation of heart cracks due to growth stress release could be interpreted by a classical mechanistic formulation. Applying Griffith theory, the possibility of the propagation is expressed by the elastic energy release rate $(\mathrm{G})$ exceeding the intrinsic toughness of the wood material in the observed direction and mode of propagation $\left(\mathrm{G}_{\mathrm{c}}\right)$. The computation of $\mathrm{G}$ was done by using the finite-elements method, for a given geometry and a fixed mesh. Assuming that the evolution of the cracks is governed, at each step, by the direction of propagation producing the greatest $\mathrm{G}$, we obtained schematic crack patterns for 16 cases combinations of wood type and density, initial growth stress distribution and internal crack shape. To reduce the number of necessary calculations we had to limit to 8 possible directions of radial propagation; this restrictive condition ought to be removed, and calculations be performed again with a refined mesh to ensure the quality of the predictions. However, for the simple purpose of studying the influence of density (and associated level of anisotropy) and reaction wood occurrence, it can be reasonably assumed that the general trends obtained here are valid. A number of generally observed facts have been confirmed by the simulation, such as the considerable increase of cracking risk in the case of tension wood occurrence in an angular sector of the log, the few problems encountered with softwood species at the crosscutting stage, or the fact that large diameter logs tend to crack more, in relative terms, than small diameter logs. Other predictions by the simulation, like the number of cracks and orientation relative to the reaction wood zones, or the increase of cracking risk with wood density, ought to be verified experimentally.

\section{References}

[1] Archer R.R., Growth stresses and strains in trees (Springer Series in Wood Science, edited by E. Timell, Springer Verlag, Berlin, Heidelberg, New York, Tokyo, 1986).

[2] Kübler H. Forest Prod. Abs. 10 (1987) 61-119.

[3] Bui H.D., Mécanique de la rupture fragile (Masson, Paris, 1978).

[4] Jullien D., Laghdir A. and Gril J., "Modelling log-end cracks due to growth stresses: calculation of the elastic energy release rate", to be published in Holzforschung.

[5] Laghdir A., "Modélisation de la fissuration en bout de grumes liée aux contraintes de croissance", PhD dissertation (Univ. Montpellier 2, 2000).

[6] Jullien D., Famiri A., Gril J. and Laghdir A., "Observation of log-end cracks caused by growth stress in Eucalyptus", 3rd Plant Biomechanics Conf., Badenweiler, Germany (Thieme-Verlag, 2000) pp. 483-486

[7] Guitard D. and El Amri F., Ann. Sci. Forestières, 4 (1987) pp. 335-358.

[8] Beauchêne J. "Evolution du comportement mécanique du bois vert avec la température. Application à l'étude du déroulage et du tranchage de quelques bois guyanais", PhD (ENGREF Kourou, Guyane, 1996). 